06,13

\title{
Структура, динамика решетки и диэлектрические характеристики пленок $\mathrm{Sr}_{0.5} \mathrm{Ba}_{0.5} \mathrm{Nb}_{2} \mathrm{O}_{6}$
}

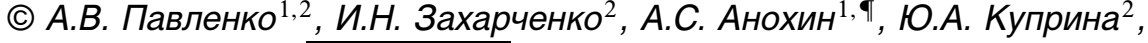 \\ Л.И Киселева ${ }^{1}$, Ю.И. ЮзюК \\ ${ }^{1}$ Южный научный центр РАН, \\ Ростов-на-Дону, Россия \\ 2 Южный федеральный университет, \\ Ростов-на-Дону, Россия \\ 『 E-mail: anokhin.andrey@gmail.com
}

(Поступила в Редакцию 12 октября 2016 г.)

Методом высокочастотного напыления в атмосфере кислорода получены пленки твердого раствора $\mathrm{Sr}_{0.5} \mathrm{Ba}_{0.5} \mathrm{Nb}_{2} \mathrm{O}_{6}$ на подложке (111)Pt/(001)Si. Изучены их деполяризованные спектры комбинационного рассеяния света, структура и диэлектрические характеристики в широком диапазоне температур. Установлено, что пленки однофазны, обладают структурой тетрагональной вольфрамовой бронзы, имеют ярко выраженную аксиальную текстуру с осью 001, направленной перпендикулярно поверхности подложки. Показано, что в интервале температур 300-425 К в материале пленки происходит размытый фазовый переход в состояние сегнетоэлектрика-релаксора. Обсуждаются возможные причины выявленных закономерностей.

Работа выполнена в рамках реализации государственного задания на 2016г № 007-01114-16 ПР (проект № 0256-2014-0002) и гранта РФФИ № 16-32-60095 мол_а_дк.

DOI: 10.21883/FTT.2017.05.44376.382

\section{1. Введение}

Твердые растворы (TP) $\mathrm{Sr}_{x} \mathrm{Ba}_{1-x} \mathrm{Nb}_{2} \mathrm{O}_{6}$ (SBN) при $0.25<x<0.75$ являются одноосными полярными соединениями со структурой тетрагональных вольфрамовых бронз (ТВБ) и обладают уникальным набором свойств (оптических, пьезоэлектрических и др.), представляющих интерес как для фундаментальных исследований, так и для прикладных целей [1]. Ниобаты стронция-бария являются типичными представителями сегнетоэлектриков-релаксоров, но в отличие от классического сегнетоэлектрика-релаксора $\mathrm{PbMg}_{1 / 3} \mathrm{Nb}_{2 / 3} \mathrm{O}_{3}$ в них в отсутствие электрического поля наблюдается переход из релаксорного в сегнетоэлектрическое (СЭ) состояние, сопровождаемое изменением симметрии и возникновением доменной структуры. СЭ-фаза TP SBN принадлежит к полярному классу $4 m m$ с пространственной симметрией $P 4 \mathrm{bm}$ [1]. Выше температуры Кюри - в параэлектрической (ПЭ) фазе - пространственная группа $P 4 b m$ трансформируется в неполярную группу $P \overline{4 b} 2$, имеющую точечный класс симметрии $\overline{4} 2 m$, при этом степенью размытия фазового перехода $(Ф П)$, его температурой и рядом оптических и электрофизических характеристик удается достаточно хорошо управлять посредством вариации состава ТР или же введения легирующих элементов [2]. В последние годы большое внимание стало уделяться созданию и исследованию гетероструктур на основе тонких пленок SBN $[3,4]$, что обусловлено стремительным развитием микроэлектроники, микроэлектромеханических систем и ряда других направлений [5], в которых нелиней- ные свойства ниобатов стронция-бария могут быть эффективно использованы. Несмотря на очевидные практические приложения, работ, посвященных комплексному изучению характеристик пленок SBN, немного. В настоящей работе представлены результаты исследования структуры, динамики решетки и диэлектрических характеристик пленок SBN в широком диапазоне температур, охватывающем область СЭ-ПЭ-фазового превращения.

\section{2. Методы получения и исследования объектов}

Газоразрядное напыление пленок на подложку (111) $\mathrm{Pt} /(001) \mathrm{Si}$ производилось в атмосфере чистого кислорода согласно методике, подробно описанной в [6]. Толщина и скорость роста пленки определялись по текущей кривой интенсивности поляризованного лазерного оптического излучения (длина волны $650 \mathrm{~nm}$ ), зеркально отраженного от поверхности подложки с растущей пленкой, по методике [7]. Керамическая мишень $\mathrm{Sr}_{0.5} \mathrm{Ba}_{0.5} \mathrm{Nb}_{2} \mathrm{O}_{6}$ диаметром $50 \mathrm{~mm}$ была изготовлена в Отделе интеллектуальных материалов и нанотехнологий НИИ физики ЮФУ [8].

Рентгенографические исследования проводились на дифрактометре ДРОН-7 (Со $K_{\alpha}$-излучение), снабженном высокотемпературной камерой НTK 1200N (Anton Paar $\mathrm{GmbH})$. Регистрация рефлексов проводилась при охлаждении образца от температуры, превышающей $700 \mathrm{~K}$, с выдержкой при каждой температуре в течение $15 \mathrm{~min}$. 
Для получения спектров комбинационного рассеяния света (КРС) использовались поляризованное излучение аргонового лазера $(\lambda=514.5 \mathrm{~nm})$ и микро-КРС спектрометр Renishaw inVia Reflex c NExT-фильтром, позволяющим записывать спектры начиная с $10 \mathrm{~cm}^{-1}$. Спектры регистрировались по схеме обратного рассеяния с помощью оптического микроскопа Leica, диаметр лазерного пучка на образце составлял $1-2 \mu \mathrm{m}$.

Верхние электроды, необходимые для проведения диэлектрических измерений, наносились через маску методом термического испарения: в качестве адгезионного подслоя использовался $\mathrm{Cr}$ (толщиной 20-40 nm), а в качестве основного - Al (толщиной 150-200 nm). Диаметр электродов был равен 20-300 $\mu \mathrm{m}$. Температурные зависимости относительной диэлектрической проницаемости $\varepsilon / \varepsilon_{0}\left(\varepsilon_{0}-\right.$ электрическая постоянная) и тангенса угла диэлектрических потерь $\operatorname{tg} \delta$ при $T=200-500 \mathrm{~K}$ в диапазоне частот $f=10^{3}-10^{6} \mathrm{~Hz}$ получались с помощью измерительного стенда на базе LCR-метра Agilent 4980А и терморегулятора Варта ТП 703.

\section{3. Экспериментальные результаты и обсуждение}

На рис. 1 приведена дифрактограмма гетероструктуры SBN/(111)Pt/(001)Si. Видно, что пленка является однофазной, обладает ярко выраженной аксиальной текстурой: рефлексы $00 l$ намного интенсивнее остальных рефлексов, принадлежащих SBN, т.е. направление [001] перпендикулярно поверхности пленки. При комнатной температуре $c=3.945 \AA$, что соответствует литературным данным [9].

Деполяризованный спектр КРС гетероструктуры $\mathrm{SBN} / \mathrm{Pt} / \mathrm{Si}$, измеренный в геометрии обратного рассеяния, при комнатной температуре приведен на рис. 2. Наибольший вклад в интенсивность спектра пленки SBN вносят три широкие полосы в районе 230, 630 и $850 \mathrm{~cm}^{-1}$, каждая из которых состоит из набора линий (линии от подложки $\mathrm{Si}$ экранируются слоем платины).

Частоты линий в спектре пленки $\mathrm{SBN} / \mathrm{Pt} / \mathrm{Si}$

\begin{tabular}{c|c|c}
\hline Мода & Частота, $\mathrm{cm}^{-1}$ & Полуширина, $\mathrm{cm}^{-1}$ \\
\hline 1 & 103.3 & 38 \\
2 & 143.7 & 24 \\
3 & 188.0 & 34 \\
4 & 230.5 & 41 \\
5 & 284.3 & 50 \\
6 & 410.8 & 7 \\
7 & 552.4 & 53 \\
8 & 602.6 & 39 \\
9 & 639.5 & 34 \\
10 & 704.7 & 60 \\
11 & 823.2 & 25 \\
12 & 855.9 & 31 \\
13 & 906.5 & 32
\end{tabular}

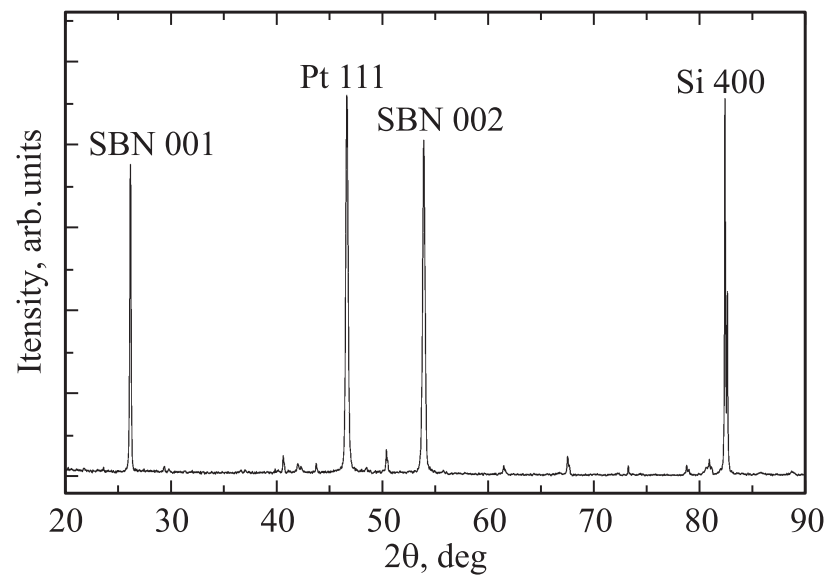

Рис. 1. Дифрактограмма гетероструктуры SBN/(111)Pt/(001)Si при комнатной температуре.

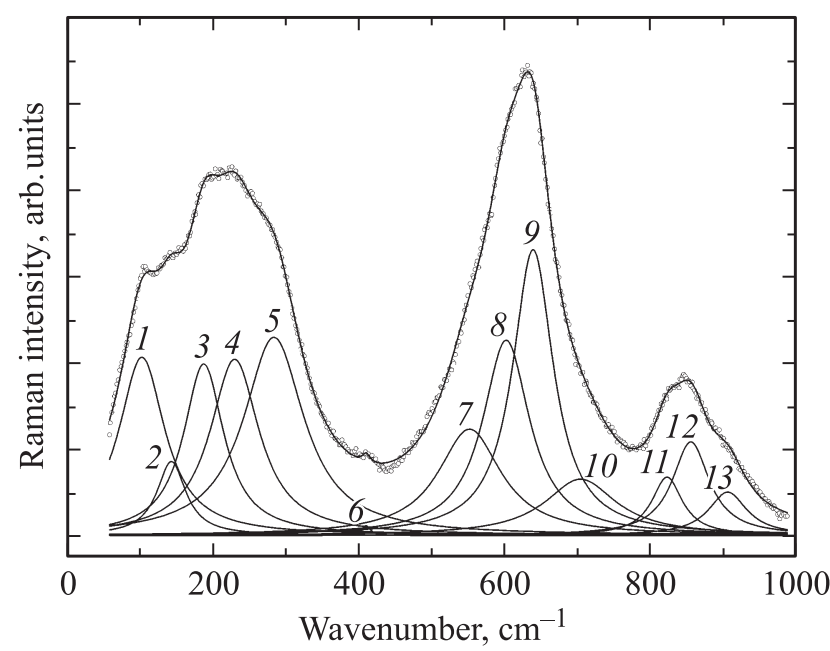

Рис. 2. Деполяризованный спектр КРС пленки $\mathrm{SBN} / \mathrm{Pt} / \mathrm{Si}$ при комнатной температуре. Частоты и полуширины мод 1-13 приведены в таблице.

Разложив данный спектр на компоненты, можно выделить тринадцать мод с частотами $v_{1}-v_{13}$ (см. таблицу). Две интенсивные линии с частотами $v_{4}$ и $v_{9}$ являются фононными модами $A_{1}(\mathrm{TO})$, которые представляют собой внутренние колебания $\mathrm{NbO}_{3}$-октаэдра, соответствующие движению ионов вдоль оси $Z$ [10]. Как было отмечено выше, ниобаты стронция-бария принадлежат к структуре ТВБ с тетрагональной точечной группой $4 \mathrm{~mm}$ и пятью формульными единицами в элементарной ячейке. Для них существует 135 колебательных мод (3 - 45), в том числе три акустические моды. Из пяти неприводимых представлений $A_{1}, A_{2}, B_{1}, B_{2}$ и $E$ только $A_{2}$ является неактивным и в спектрах КРС, и в ИК-спектрах. Моды симметрии $B$ активны в спектрах КРС, а моды $A_{1}$ и $E$ активны и в спектрах КРС, и в ИК-спектрах. Однако соответствующие линии, наблюдаемые в экспериментальных спектрах кристаллов SBN [11] и в нашем случае (рис. 2), достаточно широки, их значительно меньше, 


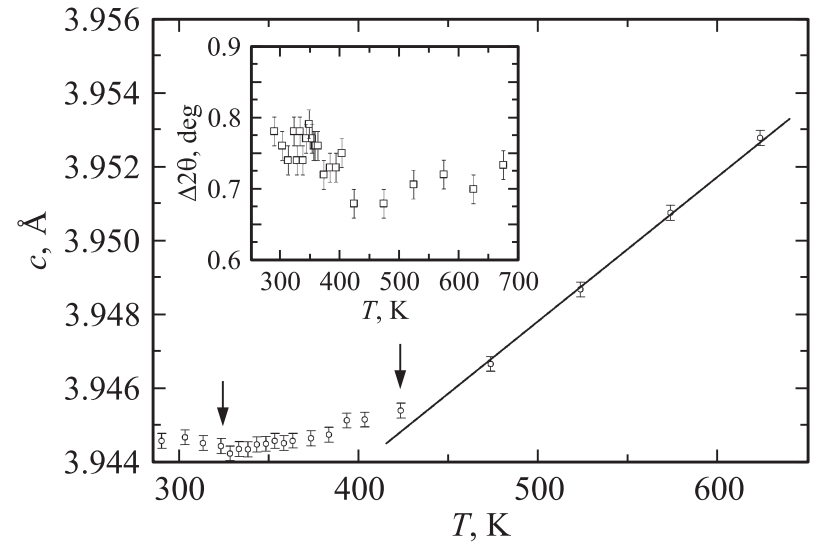

Рис. 3. Температурная зависимость параметра $c$ пленки $\mathrm{SBN}$ на подложке (111)Pt/(001)Si. На вставке - зависимость интегральной ширины $(\Delta 2 \theta)$ рефлекса 004 от температуры.

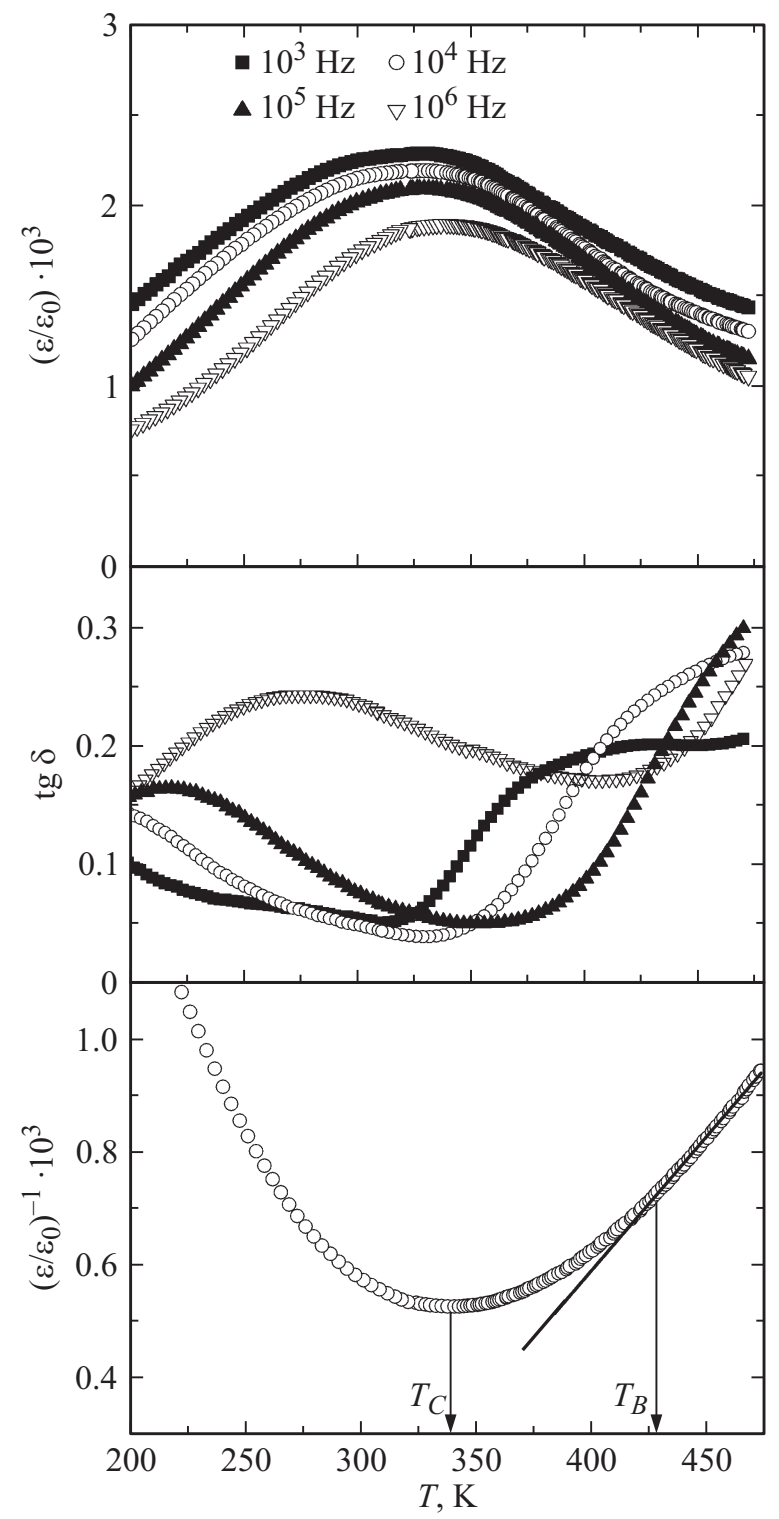

Рис. 4. Зависимости $\varepsilon / \varepsilon_{0}(T), \operatorname{tg} \delta(T)$ и $\left(\varepsilon / \varepsilon_{0}\right)^{-1}(T)$ структуры $\mathrm{Al} / \mathrm{Cr} / \mathrm{SBN}-50 /(111) \mathrm{Pt} /(001) \mathrm{Si}$ при $T=200-500 \mathrm{~K}$ на частотах $f=10^{3}, 10^{4}, 10^{5}$ и $10^{6} \mathrm{~Hz}$.

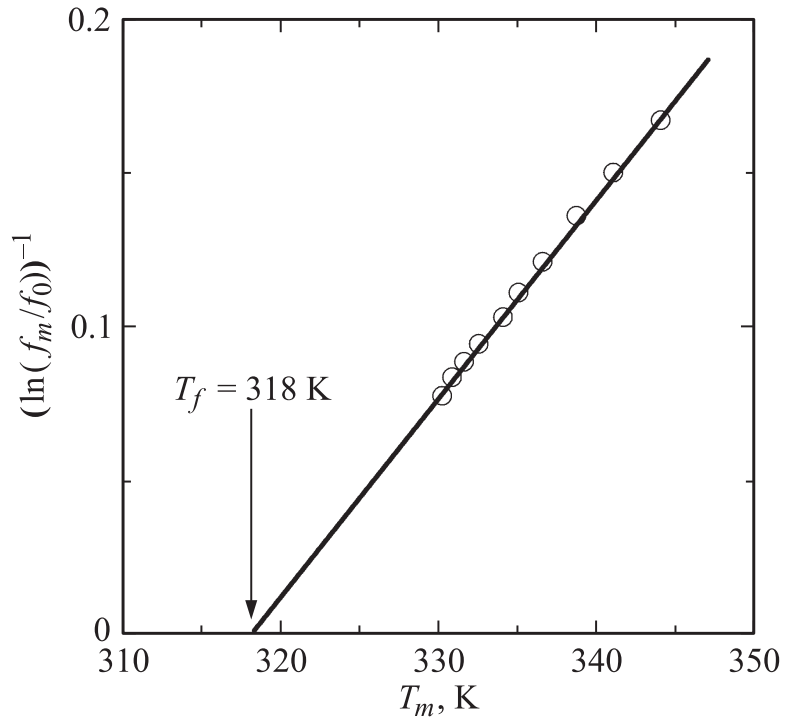

Рис. 5. Зависимость $\left(\ln \left(f_{m} / f_{0}\right)\right)^{-1}\left(T_{m}\right)$ структуры $\mathrm{Al} / \mathrm{Cr} /$ $\mathrm{SBN} /(111) \mathrm{Pt} /(001) \mathrm{Si}$. Прямая линия - результат расчета по соотношению Фогеля-Фулчера.

чем теоретически предсказанных мод [12], что связывается в первую очередь с катионной неупорядоченностью в структуре ТВБ [13] и, как следствие, с нарушением правил отбора по волновому вектору в центре зоны Бриллюэна [14]. Поскольку в элементарной ячейке SBN существуют 132 оптические фононные моды, возможно вырождение некоторых из них в одну полосу, что вносит дополнительный вклад в уширение спектра КРС. Отметим также, что в отличие от классических сегнетоэлектриков (например, $\mathrm{BaTiO}_{3}$ и его ТP [15]) в исследуемых пленках, так же как и в ряде релаксорных соединений, мягкая мода не наблюдалась [16].

На рис. 3 приведена температурная зависимость параметра $c$ пленки SBN, рассчитанного в тетрагональном приближении. При определении параметра $c$ учитывалось угловое положение четырех рефлексов $00 l$ $(l=1-4)$. На зависимости $c(T)$ имеются две особенности, соответствующие температурам 320 и $425 \mathrm{~K}$. При $T>425 \mathrm{~K}$ пленка ведет себя как сегнетоэлектрик в ПЭфазе (зависимость $c(T)$ носит линейный характер). В области $425 \mathrm{~K}$ виден скачок полуширины рентгеновских рефлексов (вставка на рис. 3). При $T<425 \mathrm{~K}$ наблюдается немонотонное изменение $c(T) \mathrm{c}$ формированием минимума при $T=320 \mathrm{~K}$, связанное, скорее всего, с особенностями перехода материала в СЭ-фазу (далее показано, что именно в этой области и локализована температура Фогеля-Фулчера).

Зависимости $\varepsilon / \varepsilon_{0}(T)$ и $\operatorname{tg} \delta(T)$ исследуемой гетероструктуры при $T=200-500 \mathrm{~K}$ и $f=10^{3}-10^{6} \mathrm{~Hz}$, полученные в режиме охлаждения, представлены на рис. 4. С ростом температуры наблюдается увеличение $\varepsilon / \varepsilon_{0}$ и формирование при $T=320-350 \mathrm{~K}\left(T_{m}\right)$ максимумов, сдвигающихся в область более высоких температур по мере увеличения $f: \Delta T=T_{m}\left(f=10^{6} \mathrm{~Hz}\right)$ 
$-T_{m}\left(f=10^{3} \mathrm{~Hz}\right)=15 \mathrm{~K}$. При $T=350-500 \mathrm{~K}$ происходит снижение $\varepsilon / \varepsilon_{0}$, сопровождающееся сначала уменьшением, а затем увеличением дисперсии. Из зависимости $\left(\varepsilon / \varepsilon_{0}\right)^{-1}(T)$ видно, что выполнение закона КюриВейсса имеет место лишь при $T>T_{B}\left(T_{B}-\right.$ температура Бернса, ниже которой появляются полярные нанообласти), а высокотемпературный склон кривой $\varepsilon / \varepsilon_{0}(T)$ при $T_{m}<T<T_{B}$ хорошо аппроксимируется функцией $\varepsilon^{-1}-\varepsilon_{m}^{-1}=\left(T-T_{m}\right)^{\gamma} / C_{1}$, где $\gamma=1.98(\gamma-$ параметр размытия $Ф П, \varepsilon_{m}$ и $T_{m}-$ соответственно высота и температура максимума $\varepsilon / \varepsilon_{0}(T)$.

При аппроксимации зависимости $T_{m}(f)$ наилучшие результаты были достигнуты в случае использования соотношения Фогеля-Фулчера $f=f_{0}$ $\times \exp \left[E_{\text {act }} /\left(k\left(T_{m}-T_{f}\right)\right)\right]$, где $f_{0}-$ частота попыток преодоления потенциального барьера $E_{\text {act }}, k-$ постоянная Больцмана, $T_{f}-$ температура Фогеля-Фулчера, интерпретируемая как температура „статического замораживания“ электрических диполей или перехода в состояние дипольного стекла (рис. 5).

\section{4. Заключение}

Полученные в работе результаты свидетельствуют о том, что в пленке SBN в интервале $300-425 \mathrm{~K}$ происходит размытый ФП из параэлектрической фазы в состояние сегнетоэлектрика-релаксора. Область ФП по сравнению с таковой для монокристаллов и керамики такого же состава [17] смещена в сторону низких температур, а степень его размытия увеличена. В работе [1] отмечалось, что наличие в структуре SBN кислородных вакансий может понижать температуру СЭ-перехода в данных соединениях, однако специфика использованного метода напыления пленок при достаточно высоких давлениях кислорода практически исключает этот механизм. Наблюдаемое поведение может быть обусловлено следующими взаимодополняющими причинами: проявлением размерных эффектов в пленочных гетероструктурах, влиянием естественных внутренних электрических полей, связанных с „захватом“ свободных носителей заряда, роль которых в пленочных структурах значительна, а также высокой чувствительностью данных структур к термодинамической предыстории. Последнее во многом обусловливается флуктуациями химического состава в структурах ТВБ [1] вследствие неупорядоченного расположения атомов $\mathrm{Ba}$ и $\mathrm{Sr}$ в структуре и различной степени заселенности четырех- и пятиугольных каналов атомами $\mathrm{Sr}[18]$ в кристаллической решетке. В пользу этого свидетельствует и достаточно большой разброс значений $T_{m}$ для керамик и кристаллов данного состава $\left(\sim 120^{\circ} \mathrm{C}[19] ; \sim 100^{\circ} \mathrm{C}[20] ; \sim 105^{\circ} \mathrm{C}[17]\right)$.

Полученные в работе результаты целесообразно использовать при получении и исследований свойств гетероструктур на основе тонких пленок ниобата стронциябария.

\section{Список литературы}

[1] Ю.С. Кузьминов. Сегнетоэлектрические кристаллы для управления лазерным излучением. Наука, М. (1982). $400 \mathrm{c}$.

[2] Т.Р. Волк, В.Ю. Салобутин, Л.И. Ивлева, Н.М. Полозков, Р. Панкрат, М. Велеке. ФТТ 42, 2066 (2000).

[3] Г.Н. Толмачев, А.П. Ковтун, И.Н. Захарченко, И.М. Алиев, А.В. Павленко, Л.А. Резниченко, И.А. Вербенко. ФТТ 57, 2050 (2015).

[4] P.R. Willmott, R. Herger, B.D. Patterson, R. Windiks. Phys. Rev. B 17, 144114 (2005).

[5] К.А. Воротилов, В.М. Мухортов, А.С. Сигов. Интегрированные сегнетоэлектрические устройства. Энергоатомиздат, М. (2011). 175 с.

[6] В.М. Мухортов, Ю.И. Головко, А.А. Маматов, Г.Н. Толмачев, С.В. Бирюков, С.И. Масычев. В сб.: Тр. ЮНЦ РАН. Ростов н/Д (2007). Т. 2. С. 224.

[7] С.П. Зинченко, А.П. Ковтун, Г.Н. Толмачев. ЖТФ 79, 11 128 (2009).

[8] А.Г. Абубакаров, И.А. Вербенко, А.В. Павленко, Г.Н. Толмачев, Л.А. Резниченко, Л.А. Шилкина, И.М. Алиев, С.Х. Алихаджиев. Изв. РАН. Сер. физ. 78, 943 (2014).

[9] T. Tsurumi, Y. Hoshino. J. Am. Ceram. Soc. 72, 278 (1989).

[10] K.G. Bartlett, L.W. Wall. J. Appl. Phys. 44, 5192 (1973).

[11] L. Peng, K. Jiang, J. Zhang, Z. Hu, G. Wang, X. Dong, J. Chu. J. Phys. D 49, 035307 (2016).

[12] E. Amzallag. J. Appl. Phys. 42, 3254 (1971).

[13] P.B. Jamieson. J. Chem. Phys. 48, 5048 (1968).

[14] R.E. Wilde. J. Raman. Spectr. 22, 321 (1991).

[15] P.-E. Janolin, A.S. Anokhin, Z. Gui, V.M. Mukhortov, Y.I. Golovko, N. Guiblin, S. Ravy, M. El Marssi, Y.I. Yuzyuk, L. Bellaiche, B. Dkhil. J. Phys.: Condens. Matter 26, 292201 (2014).

[16] М. Лайнс, А. Гласс. Сегнетоэлектрики и родственные им материалы. Мир, М. (1981). 736 с.

[17] А.В. Павленко, А.Г. Абубакаров, Л.А. Резниченко, И.М. Алиев, Л.А. Шилкина, А.В. Назаренко, И.А. Вербенко, Г.М. Константинов. ЖТФ 85, 8, 80 (2015).

[18] Т.С. Черная, Б.А. Максимов, Т.Р. Волк, Л.И. Ивлева, В.И. Симонов. ФТТ 42, 1668 (2000).

[19] A.A. Ballman, H. Brown. J. Cryst. Growth 1, 311 (1967).

[20] M.H. Francombe. Acta Cryst. 13, 131 (1960). 